\title{
Dietary arginine supplementation alleviates intestinal mucosal disruption induced by Escherichia coli lipopolysaccharide in weaned pigs
}

\author{
Yulan Liu ${ }^{1}$, Jingjing Huang ${ }^{1}$, Yongqing Hou ${ }^{1}$, Huiling $\mathrm{Zhu}^{1}$, Shengjun Zhao ${ }^{1}$, Binying Ding ${ }^{1}$, \\ Yulong Yin ${ }^{1,2}$, Ganfeng $\mathrm{Yi}^{3}$, Junxia Shi ${ }^{1}$ and Wei Fan $^{1}$ \\ ${ }^{1}$ Hubei Key Laboratory of Animal Nutrition and Feed Science, Wuhan Polytechnic University, Wuhan 430023, China \\ ${ }^{2}$ Institute of Subtropical Agriculture, Chinese Academy of Sciences, Changsha 410125, China \\ ${ }^{3}$ Animal Nutrition Research \& Development, DaChan Northeast Asia Corp., Beijing 100005, China
}

(Received 20 August 2007 - Revised 30 November 2007 - Accepted 13 December 2007 - First published online 14 February 2008)

This study evaluated whether arginine (Arg) supplementation could attenuate gut injury induced by Escherichia coli lipopolysaccharide (LPS) challenge through an anti-inflammatory role in weaned pigs. Pigs were allotted to four treatments including: (1) non-challenged control; (2) LPS-challenged control; (3) LPS $+0.5 \%$ Arg; (4) LPS $+1.0 \%$ Arg. On day 16, pigs were injected with LPS or sterile saline. At $6 \mathrm{~h}$ postinjection, pigs were killed for evaluation of small intestinal morphology and intestinal gene expression. Within $48 \mathrm{~h}$ of challenge, $0.5 \%$ Arg alleviated the weight loss induced by LPS challenge $(P=0.025)$. In all three intestinal segments, 0.5 or $1.0 \%$ Arg mitigated intestinal morphology impairment (e.g. lower villus height and higher crypt depth) induced by LPS challenge $(P<0.05)$, and alleviated the decrease of crypt cell proliferation and the increase of villus cell apoptosis after LPS challenge $(P<0.01)$. The $0.5 \%$ Arg prevented the elevation of jejunal IL-6 mRNA abundance $(P=0.082)$, and jejunal $(P=0.030)$ and ileal $(P=0.039)$ TNF- $\alpha$ mRNA abundance induced by LPS challenge. The $1.0 \%$ Arg alleviated the elevation of jejunal IL-6 mRNA abundance $(P=0.053)$ and jejunal TNF- $\alpha$ mRNA abundance $(P=0.003)$ induced by LPS challenge. The $0.5 \%$ Arg increased PPAR $\gamma$ mRNA abundance in all three intestinal segments $(P<0 \cdot 10)$, and $1.0 \%$ Arg increased duodenal PPAR $\gamma$ mRNA abundance $(P=0.094)$. These results indicate that Arg supplementation has beneficial effects in alleviating gut mucosal injury induced by LPS challenge. Additionally, it is possible that the protective effects of Arg on the intestine are associated with decreasing the expression of intestinal proinflammatory cytokines through activating PPAR $\gamma$ expression.

Arginine: Lipopolysaccharide: Weaned pigs: Intestinal morphology: Pro-inflammatory cytokines: PPAR $\gamma$

It is well documented that numerous stresses such as weaning, infection and inflammation can result in gut mucosal injury $^{(1-4)}$, and consequently result in diarrhoea and poor growth of pigs.

One emerging view is that pro-inflammatory cytokines play a critical role in gut injury ${ }^{(2)}$. Overproduction of proinflammatory cytokines can have a strongly adverse influence on gut integrity and epithelial function ${ }^{(5)}$. Therefore, controlling the release of intestinal pro-inflammatory cytokines may have potential benefits in alleviating these gut disorders.

Arginine (Arg) is a dibasic amino acid. Traditionally, it is thought of as a non-essential amino acid. However, in the last two decades, Arg has attracted major interest because it plays an important role in many physiological and biological processes including physiology of the gastrointestinal tract ${ }^{(6)}$. Arg has been shown to be effective in a number of gut injury models ${ }^{(7,8)}$. However, little research has been conducted to investigate these effects in weaned piglets.

Several studies show that Arg exerts its protective action through NO-dependent effects and NO-independent effects ${ }^{(9)}$. However, little research has been conducted to investigate the anti-inflammatory action of Arg in the gut.
In the present experiment, Escherichia coli lipopolysaccharide (LPS) was administered as an inflammatory agent to establish the model of gut injury following the model of Mercer et al. ${ }^{(10)}$. The objective was to evaluate whether Arg supplementation could attenuate the gut injury through an anti-inflammatory role and to examine the mechanism(s) of action of Arg in weaned pigs.

\section{Materials and methods}

\section{Animal care and diets}

The animal protocol for this research was approved by the Animal Care and Use Committee of Hubei Province. Seventy-two crossbred pigs (Duroc $\times$ Large White $\times$ Landrace) weaned at age $21 \pm 1 \mathrm{~d}(5.78 \pm 0.26 \mathrm{~kg})$, were balanced for initial body weight and ancestry across four treatment groups. Pigs were housed in $2.50 \times 1.80 \mathrm{~m}^{2}$ pens with six replicate pens (three pens of females and three pens of males) per treatment and three pigs per pen. Each pen was equipped with a feeder and a nipple waterer to allow pigs access $a d$ libitum to feed and water. The basal diet (Table 1) was formulated

Abbreviations: Arg, arginine; LPS, lipopolysaccharide.

* Corresponding author: Dr Yulan Liu, fax + 8627 83956175, email yulanflower@126.com 
Table 1. Ingredient composition of the basal diet (as-fed basis)

\begin{tabular}{|c|c|}
\hline & $\%$ \\
\hline \multicolumn{2}{|l|}{ Ingredient } \\
\hline Maize & $57 \cdot 40$ \\
\hline Soyabean meal, dehulled (crude protein $46.5 \%$ ) & $22 \cdot 40$ \\
\hline Wheat middling & 5.00 \\
\hline Fish meal & 3.60 \\
\hline Soya protein concentrate & 1.40 \\
\hline Fat powder* & $2 \cdot 00$ \\
\hline Whey powder & 3.00 \\
\hline Glycinet & 0.86 \\
\hline Maize starch $†$ & $0 \cdot 14$ \\
\hline Acidifierł & 0.20 \\
\hline Dicalcium phosphate & $1 \cdot 22$ \\
\hline Limestone & 0.94 \\
\hline $\mathrm{NaCl}$ & 0.34 \\
\hline L-Lysine $\cdot \mathrm{HCl}(78.8 \%$ lysine $)$ & 0.27 \\
\hline DL-Methionine ( $99 \%$ threonine) & $0 \cdot 10$ \\
\hline L-Threonine (98\% threonine) & 0.08 \\
\hline Butylated hydroquinone & 0.05 \\
\hline Vitamin and mineral premix§ & 1.00 \\
\hline \multicolumn{2}{|l|}{ Nutrient composition } \\
\hline Digestible energy (calculated; MJ/kg) & $13 \cdot 60$ \\
\hline Crude protein (analysed) & $20 \cdot 30$ \\
\hline Calcium (analysed) & 0.80 \\
\hline Total phosphorus (analysed) & 0.70 \\
\hline Total lysine (calculated) & $1 \cdot 28$ \\
\hline Total methionine + cysteine (calculated) & 0.65 \\
\hline Total arginine (calculated) & $1 \cdot 28$ \\
\hline
\end{tabular}

${ }^{*}$ A rumen-stable fat powder (purchased from Berg + Schmidt, Germany).

† In the $0.5 \%$ Arg diet, $0.86 \%$ glycine and $0.14 \%$ maize starch were replaced by $0.5 \%$ Arg, $0.43 \%$ glycine and $0.07 \%$ maize starch. In the $1.0 \%$ Arg diet, $0.86 \%$ glycine and $0.14 \%$ maize starch were replaced by $1.0 \%$ Arg. All diets were isonitrogenous.

¥A compound acidifier including lactic acid and phosphoric acid (provided by Wuhan Fanhua Biotechnology Company, Wuhan, China).

$\S$ The vitamin and mineral premix (defatted rice bran as carrier) provided the following amounts per $\mathrm{kg}$ complete diet: retinol acetate, $2700 \mu \mathrm{g}$; cholecalciferol, $62.5 \mu \mathrm{g}$; dl- $\alpha$-tocopheryl acetate, $20 \mathrm{mg}$; menadione, $3 \mathrm{mg}$; vitamin $\mathrm{B}_{12}, 18 \mu \mathrm{g}$; riboflavin, $4 \mathrm{mg}$; niacin, $40 \mathrm{mg}$; pantothenic acid, $15 \mathrm{mg}$; choline chloride, $400 \mathrm{mg}$; folic acid, $700 \mu \mathrm{g}$; thiamin, $1.5 \mathrm{mg}$; pyridoxine, $3 \mathrm{mg}$; biotin, $100 \mu \mathrm{g} ; \mathrm{Zn}, 80 \mathrm{mg}$ $\left(\mathrm{ZnSO}_{4} .7 \mathrm{H}_{2} \mathrm{O}\right) ; \mathrm{Mn}, 20 \mathrm{mg}\left(\mathrm{MnSO}_{4} .5 \mathrm{H}_{2} \mathrm{O}\right) ; \mathrm{Fe}, 83 \mathrm{mg}\left(\mathrm{FeSO}_{4} \cdot \mathrm{H}_{2} \mathrm{O}\right) ; \mathrm{Cu}, 25 \mathrm{mg}$ $\left(\mathrm{CuSO}_{4} .5 \mathrm{H}_{2} \mathrm{O}\right)$; I, $0.48 \mathrm{mg}(\mathrm{KI}) ; \mathrm{Se}, 0.36 \mathrm{mg}\left(\mathrm{Na}_{2} \mathrm{SeO}_{3} .5 \mathrm{H}_{2} \mathrm{O}\right)$.

ๆ Based on diets containing maize starch.

according to National Research Council ${ }^{(11)}$ requirements for all nutrients. All feed was pelleted. Crude protein, calcium and phosphorus of diets were analysed according to the procedures of the Association of Official Analytical Chemists ${ }^{(12)}$. Room temperature was maintained at $25-27^{\circ} \mathrm{C}$. Lighting was natural.

\section{Experimental design}

Treatments included: (1) non-challenged control (CONTR; pigs fed a control diet and injected with sterile saline); (2) LPS-challenged control (LPS; pigs fed the same control diet and challenged by injection with Escherichia coli LPS); (3) LPS $+0.5 \%$ Arg treatment (pigs fed a $0.5 \%$ Arg diet and challenged with LPS); and (4) LPS + 1.0\% Arg treatment (pigs fed a $1.0 \%$ Arg diet and challenged with LPS). The doses of Arg (L-Arg; purity $>99 \%$; Ajinomoto, Japan) were chosen because our preliminary study showed them to reduce weight loss in LPS-challenged pigs. We supplemented 0.86, 0.43 and $0 \%$ glycine (purity $>99 \%$; Ajinomoto) to the control, $0.5 \%$ Arg and $1.0 \%$ Arg diets, respectively, to obtain isonitrogenous diets according to Gurbuz et al. ${ }^{(13)}$. At 08.00 hours of day 16 , pigs were injected intraperitoneally with either $100 \mu \mathrm{g}$ E. coli LPS/ $\mathrm{kg}$ body weight or the same amount of $0.9 \%(\mathrm{w} / \mathrm{v}) \mathrm{NaCl}$ solution. The LPS (E. coli serotype 055: B5; Sigma Chemical Inc., St Louis, MO, USA) was dissolved in sterile $0.9 \% \mathrm{NaCl}$ solution (500 mg LPS/l saline). At 14.00 hours of day 16 ( $6 \mathrm{~h}$ post-challenge), one pig per pen was killed for evaluation of intestinal morphology and gene expression of pro-inflammatory cytokines and PPAR $\gamma$. To exclude the possible effects of LPS-induced food intake reduction on gastrointestinal characteristics of the slaughtered pigs, the pigs selected for slaughtering were individually transferred to an adjacent cage at 20.00 hours of day 15, and were deprived of feed until slaughter. The remaining two pigs per pen were provided feed until 08.00 hours of day 18. Body weight and feed intake were measured at 08.00 hours of days 0,16 and 18 .

\section{Sample collection}

Three castrated males and three females from each group were humanely killed by intravenous injection of sodium pentobarbital $(40 \mathrm{mg} / \mathrm{kg}$ body weight) $6 \mathrm{~h}$ following injection with LPS or saline. A midline laparotomy was performed. The abdomen was incised, and the small intestine was dissected free of the mesentery and arranged in measured lengths on a chilled stainless steel tray. The $2 \times 3,10$ and $0.5 \mathrm{~cm}$ segments were cut at every point 25,50 and $75 \%$ of the total intestinal length to represent samples for duodenum, jejunum and ileum, respectively.

The $2 \times 3 \mathrm{~cm}$ intestinal segments were processed, embedded and stained according to the procedures of Luna $^{(14)}$. The segments were flushed gently with ice-cold PBS (pH 7.4) and then fixed in $10 \%$ fresh, chilled formalin solution. The $10 \mathrm{~cm}$ intestinal segments were opened longitudinally and the contents were flushed with ice-cold PBS. The mucosa was scraped with a glass slide, snap-frozen in liquid nitrogen and then stored at $-80^{\circ} \mathrm{C}$ for further analysis of protein and DNA. The $0.5 \mathrm{~cm}$ intestinal segments were gently rinsed in ice-cold PBS and immediately frozen in liquid nitrogen, and then stored at $-80^{\circ} \mathrm{C}$ for pro-inflammatory cytokines and PPAR $\gamma$ mRNA analysis.

\section{Mucosal protein and DNA}

The mucosa samples were homogenized with a tissue homogenizer in ice-cold PBS EDTA $\left(0.05 \mathrm{M}-\mathrm{Na}_{3} \mathrm{PO}_{4}, 2.0 \mathrm{M}-\right.$ $\mathrm{NaCl}, 2 \times 10^{-3} \mathrm{M}$-EDTA, pH 7.4) using a 1:10 (w/v) ratio. Protein concentration of mucosal homogenates was measured by the method of Lowry et al. ${ }^{(15)}$ using a detergent-compatible protein assay (Bio-Rad Laboratories, Hercules, CA, USA) and bovine serum albumin as standards. Mucosal DNA content was evaluated by a fluorometric assay ${ }^{(16)}$.

\section{Intestinal morphology}

After a $24 \mathrm{~h}$ fixation, the intestinal segments were taken out, and dehydrated using increasing concentrations of ethanol (70-100\%) and chloroform. After dehydration, the segments were embedded in paraffin, and then placed in a refrigerator to make the paraffin sufficiently hard. Cross-sections of the segments were cut approximately $5 \mu \mathrm{m}$ thick with a microtome (American Optical Co., Scientific Instrument Division, 
Buffalo, NY, USA), and stained with haematoxylin and eosin. The method was according to Nabuurs et al. ${ }^{(17)}$. In each section, ten fields were examined using a light microscope with a computer-assisted morphometric system (BioScan Optimetric; BioScan Inc., Edmonds, WA, USA). The villus height and the associated crypt depth were measured. Villus height is defined as the distance from the villus tip to crypt mouth and crypt depth from crypt mouth to base.

\section{Crypt cell proliferation and villus cell apoptosis}

Crypt cell proliferation was determined using 5-bromodeoxyuridine (Roche Diagnostic Corporation, IN, USA). At $2 \mathrm{~h}$ before slaughter, 5-bromodeoxyuridine was injected intraperitoneally at $25 \mathrm{mg} / \mathrm{kg}$ body weight. Tissue slices $(5 \mu \mathrm{m})$ were deparaffinized, rehydrated and stained for bromodeoxyuridine labelling (Cell Proliferation Kit from Amersham Life Science, Amersham, UK). For each slide, the number of stained cells was counted in at least ten crypts. The proliferation index was measured as the ratio of the number of crypt cells staining positively for 5-bromodeoxyuridine and total cell number.

Villus cell apoptosis was assessed by the terminal deoxyuridine nick-end labelling immunohistochemical assay using the In Situ Cell Death Detection Kit (Boehringer Mannheim $\mathrm{GmbH}$, Mannheim, Germany). Tissue slides ( $5 \mu \mathrm{m})$ were deparaffinized, rehydrated and microwave-pretreated in $10 \mathrm{~mm}$ citrate buffer ( $\mathrm{pH} \mathrm{6.0)}$ to retrieve antigen. After washing, the slides were incubated in buffer containing a nucleotide mixture with fluorescein-labelled deoxy-UTP and terminal deoxynucleotidyl transferase at $37^{\circ} \mathrm{C}$ for $1 \mathrm{~h}$. After washing, the slides were incubated with blocking solution $\left(3 \% \mathrm{H}_{2} \mathrm{O}_{2}\right.$ in methanol) for $10 \mathrm{~min}$ and stained with anti-fluorescein antibody, Fab fragment from sheep, conjugated with horseradish peroxidase (converter-peroxidase) at $37^{\circ} \mathrm{C}$ for $30 \mathrm{~min}$. AES substrate (Zymed Laboratories Inc., San Francisco, CA, USA) was applied for colour development. For each slide, the number of stained cells was counted in at least ten villi. The apoptotic index was defined as the ratio of the number of apoptotic terminal deoxyuridine nick-end labelling-positive cells and total cell number.

\section{IL-6, TNF- $\alpha$ and PPAR $\gamma$ mRNA}

RNA was extracted from $0.5 \mathrm{~cm}$ intestinal segments using the TRIzol Reagent (Invitrogen Life Technologies, Carlsbad, CA, USA) according to manufacturer's guidelines. Each extracted RNA $(6 \mu l)$ was used as templates in cDNA synthesis. Reverse transcription was performed in a mixture of $1 \mu$ l Oligo-dT $\mathrm{d}_{18}$ (Invitrogen Life Technologies), $0.5 \mu \mathrm{l}$ RNasin inhibitor (Promega, Madison, WI, USA), $2 \mu \mathrm{l}$ dNTP (Promega), $1 \mu \mathrm{l}$ M-MLV transcriptase (Promega), $4 \mu$ l M-MLV RT reaction buffer (Promega) and 5.5 $\mu \mathrm{l}$ RNase-free water. The reaction was carried out for $5 \mathrm{~min}$ at $70^{\circ} \mathrm{C}, 1 \mathrm{~h}$ at $37^{\circ} \mathrm{C}, 5 \mathrm{~min}$ at $95^{\circ} \mathrm{C}$ and $5 \mathrm{~min}$ at $4^{\circ} \mathrm{C}$.

To amplify IL-6, TNF- $\alpha$, PPAR $\gamma$ (target gene) and $\beta$-actin cDNA fragments, the following sequences of PCR primer pairs were used: forward 5'-GGCTGCTTCTGGTGATG-

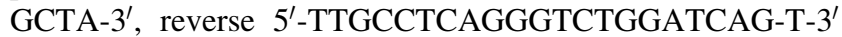
for IL-6 (419 bp); forward 5'-CCACGTTGTAGCCAATGTCA-3' ${ }^{\prime}$, reverse 5'-CAGCAAAGTCCAGATAGTCG-3' for TNF- $\alpha$ (375 bp); forward 5'-TCCCGCTGACCAAAGCAAAGGC- $3^{\prime}$, reverse $5^{\prime}$-CCACGGAGCGAAACTGACACCC- $3^{\prime}$ for PPAR $\gamma$ (195 bp); forward 5'-CGTCCACCGCAAATGCTTCTAG- $3^{\prime}$, reverse 5'-TGCTGTCACCTTCACCGTTCC- $3^{\prime}$ for $\beta$-actin (210 bp). The oligonucleotide primers of IL-6, TNF- $\alpha$, PPAR $\gamma$ and $\beta$-actin genes were designed from pig gene sequences in GenBank (M80258, X57321, AJ006757, AY550069). To minimize amplification of potentially contaminating genomic DNA, the primers were designed to span introns and intron-exon boundaries. Of the RT reaction, $1 \mu l$ of the produced cDNA was used in SYBR Green PCR Master Mix (Promega) and $0.8 \mu$ l of each $20 \mathrm{pm}$ primer. The total volume of PCR reaction system was $50 \mu$ l. Cycling parameters were $94^{\circ} \mathrm{C} \times 3 \mathrm{~min}$, followed by fifty cycles of $94^{\circ} \mathrm{C} \times 15 \mathrm{~s}, 57^{\circ} \mathrm{C} \times 30 \mathrm{~s}, 72^{\circ} \mathrm{C} \times 30 \mathrm{~s}$. Amplification products were verified by melting curves, agarose gel electrophoresis and direct sequencing. Results were analysed by the comparative cycle threshold $\left(C_{\mathrm{T}}\right)$ method $\left(2^{-\Delta \Delta C \mathrm{~T}}\right)^{(18)}$, where $C_{\mathrm{T}}$ is the number of cycles required to reach an arbitrary threshold. The validation of $\Delta \Delta C_{\mathrm{T}}$ calculation was confirmed by the following procedures. Briefly, a cDNA preparation was diluted over a 100 -fold range. For each dilution sample, amplifications were performed using target and $\beta$-actin primers. The average $C_{\mathrm{T}}$ was calculated for both target and $\beta$-actin gene and the $\Delta C_{\mathrm{T}}\left(C_{\mathrm{T} \text {,target }}-C_{\mathrm{T}, \beta \text {-actin }}\right)$ was determined. A plot of the $\log$ cDNA dilution versus $\Delta C_{\mathrm{T}}$ was made. The absolute value of the slope is close to zero, indicating the amplification efficiencies of the target and $\beta$-actin genes are similar. So, $\Delta \Delta C_{\mathrm{T}}$ calculation for the relative quantification of target genes could be used. The $C_{\mathrm{T}}$ for target gene of each sample was corrected by subtracting the $C_{\mathrm{T}}$ for $\beta$-actin $\left(\Delta C_{\mathrm{T}}\right)$. The ileal segments of the CONTR group were chosen as reference samples, and the $\Delta C_{\mathrm{T}}$ for all experimental samples was subtracted by the average $\Delta C_{\mathrm{T}}$ for the reference samples $\left(\Delta \Delta C_{\mathrm{T}}\right)$. Finally, experimental mRNA abundance relative to control mRNA abundance was calculated with use of the formula $2^{-\Delta \Delta C \mathrm{~T}}$.

\section{Statistical analysis}

All data were subjected to ANOVA appropriate for randomized complete block design by using the GLM procedure of SAS (SAS Institute, Cary, NC, USA). LPS pigs were compared by preplanned contrasts with either CONTR pigs to determine the effect of LPS challenge, or to LPS $+0.5 \%$ or $1.0 \%$ Arg pigs to determine the effect of Arg supplementation within challenged pigs. Significance of differences was calculated using the LSMEANS statement, and results are presented as least-square means and pooled standard errors of the means. Differences were considered as significant when $P<0 \cdot 05$. Instances in which $P<0 \cdot 10$ are discussed as trends.

\section{Results}

\section{Performance}

The growth performance data are presented in Table 2. There was no difference in initial body weight among treatments. During days $0-16$ (pre-challenge), there was no difference in body weight, average daily gain, average daily feed intake and gain:feed ratio among treatments. During days 16-18 (post-challenge), LPS challenge resulted in a $175 \%$ reduction of average daily gain $(P<0.001)$ and a $65 \%$ reduction of average daily feed intake $(P<0.001)$ compared 
Table 2. Effects of arginine (Arg) supplementation on the growth performance of weaned pigs during pre- and post-challenge periods* (Least-square mean values for six pens)

\begin{tabular}{|c|c|c|c|c|c|c|c|c|}
\hline & \multirow[b]{2}{*}{ CONTR } & \multirow[b]{2}{*}{ LPS } & \multirow[b]{2}{*}{ LPS $+0.5 \%$ Arg } & \multirow[b]{2}{*}{ LPS $+1.0 \% \operatorname{Arg}$} & \multirow[b]{2}{*}{ Pooled SEM } & \multicolumn{3}{|c|}{ Contrast $†$} \\
\hline & & & & & & 1 & 2 & 3 \\
\hline \multicolumn{9}{|l|}{ Body weight (kg) } \\
\hline Day 0 & 5.95 & 5.64 & 5.88 & 5.66 & 0.26 & 0.250 & 0.373 & 0.949 \\
\hline Day 16 & 8.02 & 7.87 & $7 \cdot 78$ & 8.01 & 0.60 & 0.796 & 0.878 & 0.818 \\
\hline Day 18 & 8.56 & 7.47 & 7.71 & 7.82 & 0.64 & 0.106 & 0.713 & 0.596 \\
\hline \multicolumn{9}{|c|}{ Days $0-16$ (pre-challenge) } \\
\hline ADG $(\mathrm{g})$ & 130 & 139 & 119 & 147 & 30 & 0.766 & 0.508 & 0.366 \\
\hline ADFI (g) & 252 & 243 & 227 & 287 & 47 & 0.847 & 0.742 & 0.364 \\
\hline Gain:feed ratio & 0.50 & 0.56 & 0.52 & 0.51 & 0.03 & 0.118 & 0.209 & 0.128 \\
\hline \multicolumn{9}{|c|}{ Days $16-18$ (post-challenge) } \\
\hline ADG $(\mathrm{g})$ & 267 & -200 & -33 & -97 & 69 & $<0.001$ & 0.025 & 0.149 \\
\hline ADFI (g) & 421 & 146 & 179 & 172 & 41 & $<0.001$ & 0.430 & 0.525 \\
\hline Gain:feed ratio & 0.61 & NC & NC & NC & NC & & & \\
\hline \multicolumn{9}{|c|}{ Days $0-18$ (pre-challenge and post-challenge) } \\
\hline$A D G(g)$ & 145 & 102 & 102 & 120 & 29 & 0.148 & 0.991 & 0.537 \\
\hline ADFI (g) & 271 & 232 & 222 & 274 & 44 & 0.389 & 0.816 & 0.353 \\
\hline Gain:feed ratio & 0.52 & 0.42 & 0.45 & 0.42 & 0.05 & 0.070 & 0.660 & 0.999 \\
\hline
\end{tabular}

ADFI, average daily feed intake; ADG, average daily gain; NC, not calculated.

${ }^{*}$ CONTR (non-challenged control): pigs fed a control diet and injected with sterile saline; LPS (lipopolysaccharide-challenged control): pigs fed the same control diet and challenged with Escherichia coli LPS; LPS + 0.5\% Arg:pig fed a 0.5\% Arg diet and challenged with LPS; LPS + 1.0 \% Arg:pig fed a 1.0\% Arg diet and challenged with LPS.

†Contrast: (1) CONTR v. LPS; (2) LPS v. LPS + $0.5 \%$ Arg; (3) LPS v. LPS $+1.0 \%$ Arg.

to the CONTR pigs. Dietary supplementation of $0.5 \%$ Arg significantly alleviated the weight loss compared to the LPS pigs $(P=0.025)$. Supplementation of $1.0 \%$ Arg also showed a similar pattern numerically, however, this effect did not achieve statistical significance $(P=0 \cdot 149)$. Dietary supplementation of 0.5 or $1.0 \%$ Arg did not affect average daily feed intake compared to the LPS pigs. All pigs subjected to the LPS challenge lost weight, so we did not calculate gain:feed ratio for these groups.

During the $18 \mathrm{~d}$ study, there were no differences among treatments in overall average daily gain and average daily feed intake. The LPS pigs had a $19 \%$ lower gain:feed ratio $(P=0.070)$ compared to the CONTR pigs. Arg supplementation did not affect gain:feed ratio compared to the LPS pigs.

\section{Mucosal protein and DNA}

The data for intestinal mucosal protein and DNA contents are presented in Table 3. The LPS pigs had decreased mucosal protein content in duodenum (26\% lower, $P=0.002)$ and jejunum (30\% lower, $P=0.015)$ compared to the CONTR pigs. In addition, the LPS pigs also showed a significant decrease in DNA content in jejunum (36\% lower, $P=0 \cdot 006)$ and ileum (36\% lower, $P<0.001$ ) compared to the CONTR pigs. Compared to the LPS pigs, the LPS $+0.5 \%$ Arg pigs had increased protein content in duodenum $(23 \%$ higher, $P=0.034)$ and jejunum (31\% higher, $P=0.071)$, and increased DNA content in jejunum (33\% higher, $P=0.089$ ). Compared to the LPS pigs, the LPS $+1.0 \%$ Arg pigs had increased protein content in duodenum (19\% higher, $P=0.076)$ and jejunum (31\% higher, $P=0.071)$, and increased DNA content in ileum (34\% higher, $P=0.005)$.

\section{Intestinal morphology}

Data for small intestinal morphology are shown in Table 4. Compared to CONTR pigs, LPS pigs showed a decrease in villus height in duodenum ( $30 \%$ lower, $P<0.001)$, jejunum

Table 3. Effects of arginine (Arg) supplementation on intestinal mucosal protein and DNA contents (expressed as mg/g mucosa) of weaned pigs after $6 \mathrm{~h}$ Escherichia coli lipopolysaccharide (LPS) challenge*

(Least-square mean values for six pigs)

\begin{tabular}{|c|c|c|c|c|c|c|c|c|}
\hline & \multirow[b]{2}{*}{ CONTR } & \multirow[b]{2}{*}{ LPS } & \multirow[b]{2}{*}{ LPS $+0.5 \%$ Arg } & \multirow[b]{2}{*}{ LPS $+1.0 \% \operatorname{Arg}$} & \multirow[b]{2}{*}{ Pooled SEM } & \multicolumn{3}{|c|}{ Contrast $†$} \\
\hline & & & & & & 1 & 2 & 3 \\
\hline \multicolumn{9}{|l|}{ Protein } \\
\hline Duodenum & 80.53 & $59 \cdot 24$ & $72 \cdot 89$ & 70.43 & 5.99 & 0.002 & 0.034 & 0.076 \\
\hline Jejunum & $92 \cdot 81$ & 64.86 & 84.87 & 84.92 & 10.50 & 0.015 & 0.071 & 0.071 \\
\hline lleum & 74.55 & 69.67 & 75.58 & 59.33 & 8.74 & 0.583 & 0.507 & 0.250 \\
\hline \multicolumn{9}{|l|}{ DNA } \\
\hline Duodenum & 0.750 & 0.741 & 0.729 & 0.585 & 0.137 & 0.945 & 0.934 & 0.268 \\
\hline Jejunum & $1 \cdot 102$ & 0.700 & 0.931 & 0.823 & 0.129 & 0.006 & 0.089 & 0.353 \\
\hline lleum & 1.174 & 0.750 & 0.808 & 1.004 & 0.081 & $<0.001$ & 0.485 & 0.005 \\
\hline
\end{tabular}

${ }^{*}$ CONTR (non-challenged control): pigs fed a control diet and injected with sterile saline; LPS (LPS-challenged control): pigs fed the same control diet and challenged with Escherichia coli LPS; LPS + 0.5\% Arg:pig fed a $0.5 \%$ Arg diet and challenged with LPS; LPS + 1.0\% Arg:pig fed a $1.0 \%$ Arg diet and challenged with LPS. † Contrast: (1) CONTR v. LPS; (2) LPS v. LPS + 0.5\% Arg; (3) LPS v. LPS + $1.0 \%$ Arg. 
Table 4. Effects of arginine (Arg) supplementation on villus height and crypt depth of weaned pigs after $6 \mathrm{~h}$ Escherichia coli lipopolysaccharide (LPS) challenge*

(Least-square mean values for six pigs)

\begin{tabular}{|c|c|c|c|c|c|c|c|c|}
\hline & \multirow[b]{2}{*}{ CONTR } & \multirow[b]{2}{*}{ LPS } & \multirow[b]{2}{*}{ LPS $+0.5 \%$ Arg } & \multirow[b]{2}{*}{ LPS $+1.0 \%$ Arg } & \multirow[b]{2}{*}{ Pooled SEM } & \multicolumn{3}{|c|}{ Contrast† } \\
\hline & & & & & & 1 & 2 & 3 \\
\hline Duodenum & 365 & 255 & 328 & 349 & 19 & $<0.001$ & 0.001 & $<0.001$ \\
\hline Jejunum & 376 & 268 & 323 & 334 & 13 & $<0.001$ & $<0.001$ & $<0.001$ \\
\hline Ileum & 335 & 277 & 352 & 332 & 17 & 0.003 & $<0.001$ & 0.005 \\
\hline \multicolumn{9}{|c|}{ Crypt depth $(\mu \mathrm{m})$} \\
\hline Jejunum & 190 & 231 & 174 & 151 & 21 & 0.066 & 0.013 & 0.001 \\
\hline Ileum & 169 & 236 & 199 & 187 & 17 & 0.001 & 0.043 & 0.009 \\
\hline
\end{tabular}

${ }^{*}$ CONTR (non-challenged control): pigs fed a control diet and injected with sterile saline; LPS (LPS-challenged control): pigs fed the same control diet and challenged with Escherichia coli LPS; LPS + 0.5\% Arg:pig fed a $0.5 \%$ Arg diet and challenged with LPS; LPS + 1.0\% Arg:pig fed a $1.0 \%$ Arg diet and challenged with LPS. † Contrast: (1) CONTR $v$. LPS; (2) LPS v. LPS + 0.5\% Arg; (3) LPS v. LPS + $1.0 \%$ Arg.

(29\% lower, $P<0.001)$ and ileum (17\% lower, $P=0.003)$, and also an increase in crypt depth in duodenum (13\% higher, $P=0.080)$, jejunum (22\% higher, $P=0.066)$ and ileum $(40 \%$ higher, $P=0 \cdot 001)$. Relative to LPS pigs, dietary supplementation of $0.5 \%$ Arg significantly increased villus height in duodenum (29\% higher, $P=0.001)$, jejunum (21\% higher, $P<0.001)$ and ileum (27\% higher, $P<0.001$ ), and also significantly decreased crypt depth in duodenum (25\% lower, $P<0.001)$, jejunum (25\% lower, $P=0.013)$ and ileum $(16 \%$ lower, $P=0.043)$. Supplementation of $1.0 \%$ Arg also exerted similar effects on villus height and crypt depth.

\section{Enterocyte proliferation and apoptosis}

The data for enterocyte proliferation and apoptosis are presented in Table 5. A significant decrease in crypt cell proliferation index was observed in duodenum $(34 \%$ lower, $P<0.001)$, jejunum (36\% lower, $P<0.001)$ and ileum $(36 \%$ lower, $P<0 \cdot 001$ ) in LPS pigs compared to CONTR pigs. Supplementation with $0.5 \%$ Arg resulted in a significant increase in crypt cell proliferation index in duodenum (29\% higher, $P=0.005)$, jejunum (39\% higher, $P=0.002)$ and ileum (52\% higher, $P<0.001)$ compared to LPS pigs. Supplementation with $1.0 \%$ Arg also exerted similar effects on crypt cell proliferation.
Following LPS injection, a significant increase in villus cell apoptosis index was seen in duodenum $(136 \%$ higher, $P<0.001)$, jejunum (163\% higher, $P<0.001)$ and ileum (101\% higher, $P<0.001)$ compared to CONTR pigs. Dietary supplementation of $0.5 \%$ Arg decreased villus cell apoptosis index in duodenum (32\% lower, $P=0.002)$, jejunum ( $44 \%$ lower, $P<0.001)$ and ileum (35\% lower, $P<0.001$ ) compared to LPS pigs. Supplementation with $1.0 \%$ Arg also exerted similar effects on villus cell apoptosis.

\section{mRNA expression of intestinal pro-inflammatory cytokines and PPAR $\gamma$}

The data for mRNA expression of IL- 6, TNF- $\alpha$ and PPAR $\gamma$ are shown in Table 6. LPS challenge increased IL-6 mRNA abundance in duodenum ( $81 \%$ higher, $P=0 \cdot 080)$ and jejunum (3.52-fold higher, $P<0.001)$ compared to CONTR pigs. Compared to LPS pigs, exposure to 0.5 and $1.0 \%$ Arg decreased IL-6 mRNA abundance in jejunum by $36 \%(P=0.082)$ and $41 \%(P=0.053)$, respectively.

LPS administration resulted in a significant increase in TNF- $\alpha$ mRNA abundance in duodenum (2.35-fold higher, $P=0.003)$, jejunum (4.55-fold higher, $P<0.001)$ and ileum (4.24-fold higher, $P<0.001)$ compared to CONTR pigs.

Table 5. Effects of arginine (Arg) supplementation on enterocyte proliferation and apoptosis of weaned pigs after $6 \mathrm{~h}$ Escherichia coli lipopolysaccharide (LPS) challenge*

(Least-square mean values for six pigs)

\begin{tabular}{|c|c|c|c|c|c|c|c|c|}
\hline & \multirow[b]{2}{*}{ CONTR } & \multirow[b]{2}{*}{ LPS } & \multirow[b]{2}{*}{ LPS $+0.5 \%$ Arg } & \multirow[b]{2}{*}{ LPS $+1.0 \% \operatorname{Arg}$} & \multirow[b]{2}{*}{ Pooled SEM } & \multicolumn{3}{|c|}{ Contrast $†$} \\
\hline & & & & & & 1 & 2 & 3 \\
\hline Duodenum & $45 \cdot 6$ & 29.9 & 38.5 & $47 \cdot 5$ & $2 \cdot 7$ & $<0.001$ & 0.005 & $<0.001$ \\
\hline Jejunum & $45 \cdot 8$ & $29 \cdot 3$ & $40 \cdot 8$ & $46 \cdot 7$ & $3 \cdot 3$ & $<0.001$ & 0.002 & $<0.001$ \\
\hline Ileum & $44 \cdot 8$ & $28 \cdot 5$ & $43 \cdot 3$ & $45 \cdot 5$ & $2 \cdot 6$ & $<0.001$ & $<0.001$ & $<0.001$ \\
\hline \multicolumn{9}{|c|}{ Apoptosis index (\%) } \\
\hline Jejunum & 3.43 & $9 \cdot 02$ & $5 \cdot 07$ & 5.96 & 0.91 & $<0.001$ & $<0.001$ & 0.003 \\
\hline Ileum & 3.94 & $7 \cdot 91$ & $5 \cdot 11$ & $5 \cdot 42$ & 0.37 & $<0.001$ & $<0.001$ & $<0.001$ \\
\hline
\end{tabular}

${ }^{\star}$ CONTR (non-challenged control): pigs fed a control diet and injected with sterile saline; LPS (LPS-challenged control): pigs fed the same control diet and challenged with Escherichia coli LPS; LPS + 0.5\% Arg:pig fed a $0.5 \%$ Arg diet and challenged with LPS; LPS + 1.0\% Arg:pig fed a $1.0 \%$ Arg diet and challenged with LPS. †Contrast: (1) CONTR v. LPS; (2) LPS v. LPS + 0.5\% Arg; (3) LPS v. LPS + $1.0 \%$ Arg. 
Table 6. Effects of arginine (Arg) supplementation on intestinal IL-6, TNF- $\alpha$ and PPAR $\gamma$ mRNA abundance of weaned pigs after $6 \mathrm{~h}$ Escherichia coli lipopolysaccharide (LPS) challenge*

(Least-square mean values for six pigs)

\begin{tabular}{|c|c|c|c|c|c|c|c|c|}
\hline & \multirow[b]{2}{*}{ CONTR } & \multirow[b]{2}{*}{ LPS } & \multirow[b]{2}{*}{ LPS $+0.5 \%$ Arg } & \multirow[b]{2}{*}{ LPS $+1.0 \%$ Arg } & \multirow[b]{2}{*}{ Pooled SEM } & \multicolumn{3}{|c|}{ Contrast† } \\
\hline & & & & & & 1 & 2 & 3 \\
\hline Duodenum & 1.84 & $3 \cdot 33$ & $2 \cdot 42$ & $3 \cdot 16$ & 0.81 & 0.080 & 0.271 & 0.834 \\
\hline Jejunum & $2 \cdot 38$ & $10 \cdot 75$ & $6 \cdot 86$ & $6 \cdot 39$ & $2 \cdot 12$ & $<0.001$ & 0.082 & 0.053 \\
\hline Ileum & 1.07 & $2 \cdot 21$ & 1.82 & 1.98 & 0.68 & 0.109 & 0.577 & 0.738 \\
\hline \multicolumn{9}{|l|}{ TNF- $\alpha$} \\
\hline Jejunum & 2.91 & $16 \cdot 16$ & $10 \cdot 58$ & $8 \cdot 15$ & $2 \cdot 38$ & $<0.001$ & 0.030 & 0.003 \\
\hline Ileum & $1 \cdot 10$ & $5 \cdot 76$ & 3.99 & 4.61 & 0.80 & $<0.001$ & 0.039 & 0.166 \\
\hline \multicolumn{9}{|l|}{ PPAR $\gamma$} \\
\hline Duodenum & $2 \cdot 87$ & $4 \cdot 25$ & $6 \cdot 34$ & $6 \cdot 21$ & $1 \cdot 12$ & 0.234 & 0.075 & 0.094 \\
\hline Jejunum & $5 \cdot 18$ & $15 \cdot 24$ & $24 \cdot 32$ & $18 \cdot 83$ & 2.99 & 0.003 & 0.006 & 0.243 \\
\hline Ileum & 1.07 & 1.53 & 3.09 & 2.55 & 0.79 & 0.561 & 0.063 & 0.214 \\
\hline
\end{tabular}

* CONTR (non-challenged control): pigs fed a control diet and injected with sterile saline; LPS (LPS-challenged control): pigs fed the same control diet and challenged with Escherichia coli LPS; LPS + 0.5\% Arg:pig fed a $0.5 \%$ Arg diet and challenged with LPS; LPS $+1.0 \%$ Arg:pig fed a $1.0 \%$ Arg diet and challenged with LPS. † Contrast: (1) CONTR $v$. LPS; (2) LPS v. LPS + $0.5 \%$ Arg; (3) LPS v. LPS + $1.0 \%$ Arg.

Relative to LPS pigs, dietary supplementation of $0.5 \% \mathrm{Arg}$ decreased TNF- $\alpha$ mRNA abundance in jejunum (35\% lower, $P=0.030$ ) and ileum (31\% lower, $P=0.039)$, and $1.0 \%$ Arg supplementation decreased TNF- $\alpha$ mRNA abundance in jejunum (50\% lower, $P=0.003)$.

LPS injection increased PPAR $\gamma$ mRNA abundance by $194 \%$ in jejunum $(P=0.003)$. Compared to the LPS pigs, $0.5 \%$ Arg supplementation increased PPAR $\gamma$ mRNA abundance in duodenum (49\% higher, $P=0.075)$, jejunum (60\% higher, $P=0.006)$ and ileum (102\% higher, $P=0.063)$, and $1.0 \%$ Arg supplementation increased PPAR $\gamma$ mRNA abundance by $46 \%$ in duodenum $(P=0.094)$.

\section{Discussion}

In the present study, to evaluate whether Arg supplementation could attenuate gut injury through an anti-inflammatory role in weaned pigs, we took advantage of a model for inducing gut injury in pigs by injecting Escherichia coli LPS $^{(10)}$. LPS is a molecule found in the membrane of all gram-negative bacteria. LPS induces symptoms of acute bacterial infection including anorexia, hypersomnia and fever. In addition, LPS results in a variety of morphological alterations in the digestive tract, such as submucosal oedema, epithelial lifting at the tips of villi, frank haemorrhage and necrosis ${ }^{(10)}$, ileal mucosal acidosis ${ }^{(19)}$, and results in an increase in mucosal permeability ${ }^{(20)}$. Besides the direct effect of LPS on gut, LPS may induce indirectly intestinal injury via reduced feed intake. It has been shown that feed intake is correlated with intestinal morphology ${ }^{(21)}$. In the current study, the pigs were deprived of feed after $6 \mathrm{~h}$ LPS challenge (i.e. before slaughter), which excludes the possible effects of feed intake on gastrointestinal characteristics.

In the present study, LPS challenge severely decreased performance of weaned pigs during $48 \mathrm{~h}$ post-challenge, which is consistent with the findings of Johnson ${ }^{(22)}$ and Liu et al. ${ }^{(23)}$. Prior to LPS challenge, Arg supplementation had no effect on growth performance of weaned pigs. In contrast to the present findings, Kim et al. ${ }^{(24)}$ reported that dietary supplementation with 0.2 and $0.4 \%$ Arg to milk-fed piglets improved growth performance. Additionally, Takahashi et al. ${ }^{(25)}$ reported that Arg supplementation improved body weight gain and feed efficiency in male broiler chickens. The reason for the discrepancy might be that the Arg level of the basal diet (1.28\%) in the current study was adequate for maintaining growth of weaned pigs in normal physiological condition. During $48 \mathrm{~h}$ post-challenge, $0.5 \%$ Arg supplementation alleviated the weight loss compared to the LPS pigs, which indicates the importance of exogenous Arg supply under stress, infection and diseases. Similarly, Kohli et al. ${ }^{(26)}$ reported that daily oral administration of $\mathrm{L}-\mathrm{Arg}-\mathrm{HCl}$ reduced body weight loss in streptozotocin-induced diabetic rats. It has been reported that Arg may act as a metabolic regulator to increase protein synthesis and decrease protein catabolism under infection and stress situations ${ }^{(27)}$ by stimulating the secretion of insulin, growth hormone and glucagon ${ }^{(28)}$. Therefore, it is possible that $0.5 \%$ Arg supplementation alleviated growth suppression associated with the LPS challenge partially by decreasing protein catabolism and maintaining the protein deposition rate of skeletal muscle.

Mucosal protein and DNA contents are important indicators for cell metabolism. Villus height and crypt depth can be regarded as a criterion to reflect intestinal morphology. In the present study, compared to the LPS pigs, 0.5 or $1.0 \%$ Arg supplementation increased mucosal protein and DNA contents, and increased villus height and decreased crypt depth following Arg supplementation, which indicates that Arg supplementation protected the intestinal mucosa from damage caused by the LPS challenge. In agreement with the present findings, Sukhotnik et al. ${ }^{(7)}$ reported that oral Arg improved intestinal recovery following ischaemia-reperfusion injury in rats. In addition, dietary Arg supplementation accelerated ulcer healing in experimental ulcerative ileitis ${ }^{(29)}$ and stimulated small intestinal mucosal recovery following experimental radiation enteritis ${ }^{(13)}$. In the current experiment, improvement of intestinal mucosa is concurrent with alleviation of growth suppression induced by LPS challenge following $0.5 \%$ Arg supplementation. Therefore, it is possible that feeding Arg in the diet to the LPS-challenged pigs attenuated growth depression partially by alleviating the 
intestinal mucosa injury. However, in contrast to $0.5 \%$ Arg supplementation, $1.0 \%$ Arg supplementation alleviated intestinal mucosa injury, but did not alleviate growth suppression significantly. The reason for the discrepancy might be that over-supplementation of Arg resulted in Arg-lysine antagonism, and lowered the absorption of lysine ${ }^{(30)}$, or resulted in a general amino acid imbalance ${ }^{(31)}$, and consequently counteracted the advantage of $1.0 \%$ Arg supplementation on growth performance of the challenged pigs.

The dynamic process of epithelial cell turnover is a function of the rates of crypt cell proliferation, migration along the small intestine crypt-villus axis, differentiation and cell death via apoptosis ${ }^{(7)}$. To some degree, normal intestinal morphology depends on the balance of epithelial cell turnover ${ }^{(7)}$. Decreased cell proliferation and increased apoptosis may be the main mechanisms responsible for intestinal mucosal injury ${ }^{(7)}$. In the present study, dietary supplementation of Arg attenuated the decrease of crypt cell proliferation and the increase of villus cell apoptosis caused by the LPS challenge. The present findings are consistent with the results of Sukhotnik et al. ${ }^{(7)}$ who reported that Arg increased mucosal cell proliferation in functioning intestine and decreased the cell apoptosis in ileum in rats suffering from ischaemia-reperfusion injury. Additionally, some research has shown that Arg stimulated intestinal epithelial cell migration ${ }^{(32,33)}$. In the current study, feeding Arg in the diet to the LPS-challenged pigs may alleviate the intestinal mucosa injury via maintaining the balance of epithelial cell turnover.

In the current study, we hypothesized that Arg exerted its protective effect on the gut through attenuating intestinal inflammatory response. Consistent with mucosal injury caused by the LPS challenge, increased expression of IL-6 in duodenum and jejunum, and TNF- $\alpha$ in all three intestinal segments was observed. In agreement with the present observations, many studies have reported the up-regulated expression of pro-inflammatory cytokines in the intestine of man and animals during enteric infection and intestinal inflammatory diseases ${ }^{(34)}$ and in newly weaned pigs ${ }^{(2)}$. Over-production of pro-inflammatory cytokines can have a negative influence on gut integrity and epithelial function ${ }^{(5)}$. In the present study, the LPS pigs fed the $0.5 \%$ Arg diet exhibited decreased jejunal IL-6, jejunal and ileal TNF- $\alpha$ mRNA, and those fed the $1.0 \%$ Arg diet exhibited decreased jejunal TNF- $\alpha$ mRNA compared to the LPS pigs. Currently, there are very few studies on the regulation of intestinal pro-inflammatory cytokines through dietary Arg supplementation. Marion et al. ${ }^{(35)}$ reported that Arg reduced CXC chemokines (e.g. IL-8 and Mig) in the human intestinal epithelial cell line HCT-8 under inflammatory conditions, which suggests that Arg exerted beneficial influence on intestinal inflammatory response. In addition, Arg exerted an inhibitory effect on pro-inflammatory cytokine production in many other stress models ${ }^{(8,36,37)}$. Arg down-regulated pro-inflammatory cytokine expression or production in spleen, thymus, lung and liver of burned rats ${ }^{(36)}$, in serum and lung of immature rats after gut ischaemia-reperfusion ${ }^{(8)}$, and in peritoneal lavage fluid of septic rat ${ }^{(37)}$, thus preventing the development of inflammation. In the current study, it is possible that feeding pigs dietary Arg reduced gut mucosal injury partially by suppressing pro-inflammatory cytokine production.

To explore the molecular mechanism by which Arg attenuated intestinal inflammatory response, we examined the role of
PPAR $\gamma$. PPAR $\gamma$, a member of the superfamily of nuclear hormone receptors, has recently been recognized as an endogenous regulator of intestinal inflammation ${ }^{(38,39)}$. PPAR $\gamma$ ligands have been shown to be effective in a number of intestinal inflammatory models ${ }^{(40,41)}$. The protective effects of PPAR $\gamma$ and its ligands is associated with the inhibition of a wide variety of inflammatory indices such as pro-inflammatory cytokines $^{(42)}$. The mechanism of action of PPAR $\gamma$ in inflammation is in the trans-suppression of pro-inflammatory cytokine gene activation by negatively interfering with the NF-кB, STAT-1 and AP-1 signalling pathways ${ }^{(42)}$.

In the present study, we have observed for the first time that intestinal PPAR $\gamma$ expression is up-regulated and the synthesis of intestinal IL- 6 and TNF- $\alpha$ were decreased simultaneously in Arg-supplemented pigs after LPS challenge. So, it is possible that the protective effects of Arg on intestinal mucosal injury were associated with decreasing the expression of intestinal pro-inflammatory cytokines through activating PPAR $\gamma$ expression. The inhibitory effect of PPAR $\gamma$ on pro-inflammatory cytokines could be mediated through the inhibition of NF$\kappa \mathrm{B}$. Indeed, in a rat model of LPS-induced injury ${ }^{(43)}$, Arg inhibited the NF- $\kappa$ B DNA binding and stabilized I- $\kappa$ B complex, which both may account for the decreased pro-inflammatory cytokines. Additionally, a study has shown that activation of PPAR $\gamma$ in the colon inhibits mucosal production of IL-1 $\beta$ and TNF- $\alpha$ by down-regulation of the NF- $\mathrm{KB}$ and mitogenactivated protein kinase signal pathways ${ }^{(44)}$. Regretfully, in the current study, no categorical evidence demonstrated that Arg was working directly through PPAR $\gamma$. Further studies are needed to accomplish it either by including a PPAR $\gamma$ antagonist or by knocking out or down the expression of PPAR $\gamma$ in the experimental designs.

In conclusion, dietary supplementation of Arg exerts beneficial effects in alleviating gut mucosal injury of LPS-challenged pigs. It is possible that the protective effects of Arg on the intestine are associated with decreasing the expression of intestinal pro-inflammatory cytokines through activating PPAR $\gamma$ expression.

\section{Acknowledgements}

The authors express their gratitude to the National Basic Research Program of China (2004CB117504), the National Natural Science Foundation of China (30500362) and the Hubei Provincial Department of Education (D200718003) for financial support. There is no conflict of interest that should be disclosed.

\section{References}

1. Touchette KJ, Carroll JA, Allee GL, Matteri RL, Dyer CJ, Beausang LA \& Zannelli ME (2002) Effect of spray-dried plasma and lipopolysaccharide exposure on weaned pigs: I. Effects on the immune axis of weaned pigs. J Anim Sci 80, 494-501.

2. Pié S, Lallès JP, Blazy F, Laffitte J, Sève B \& Oswald IP (2004) Weaning is associated with an upregulation of expression of inflammatory cytokines in the intestine of piglets. J Nutr 134, 641-647.

3. Yi GF, Carroll JA, Allee GL, Gaines AM, Kendall DC, Usry JL, Toride Y \& Izuru S (2005) Effect of glutamine and spray-dried 
plasma on growth performance, small intestinal morphology, and immune responses of Escherichia coli $\mathrm{K}^{2} 8^{+}$-challenged weaned pigs. J Anim Sci 83, 634-643.

4. Blikslager AT, Moeser AJ, Gookin JL, Jones SL \& Odle J (2007) Restoration of barrier function in injured intestinal mucosa. Physiol Rev 87, 545-564.

5. Mckay DM \& Baird AW (1999) Cytokine regulation of epithelial permeability and ion transport. Gut 44, 283-289.

6. Anggard E (1994) Nitric oxide: mediator, murderer, and medicine. Lancet 14, 1199-1206.

7. Sukhotnik I, Helou H, Mogilner J, Lurie M, Bernsteyn A, Coran AG \& Shiloni E (2005) Oral arginine improves intestinal recovery following ischemia-reperfusion injury in rat. Pediatr Surg Int 21, 191-196.

8. Fu TL, Zhang WT, Zhang L, Wang F, Gao Y \& Xu M (2005) L-Arginine administration ameliorates serum and pulmonary cytokine response after gut ischemia-reperfusion in immature rats. World J Gastroenterol 11, 1070-1072.

9. Duggan C, Gannon J \& Walker WA (2002) Protective nutrients and functional foods for the gastrointestinal tract. Am J Clin Nutr 75, 789-808.

10. Mercer DW, Smith GS, Cross JM, Russell DH, Chang L \& Cacioppo J (1996) Effects of lipopolysaccharide on intestinal injury: potential role of nitric oxide and lipid peroxidation. J Surg Res 63, 185-192.

11. National Research Council (1998) Nutrient Requirements of Swine, 10th ed. Washington, DC: National Academy Press.

12. Association of Official Analytical Chemists (1990) Official Methods of Analysis, 15th ed. Washington, DC: AOAC.

13. Gurbuz AT, Kunzelman J \& Ratzer EE (1998) Supplemental dietary arginine accelerates intestinal mucosal regeneration and enhances bacterial clearance following radiation enteritis in rats. $J$ Surg Res 74, 149-154.

14. Luna LG (1968) Manual of Histologic Staining Methods of the Armed Forces Institute of Pathology, 3rd ed. New York: McGraw-Hill Book Company.

15. Lowry OH, Rosebrough NJ, Farr AL \& Randall RJ (1951) Protein measurement with Folin phenol reagent. J Biol Chem 193, 265-275.

16. Labarca C \& Paigen K (1980) A simple, rapid, and sensitive DNA assay procedure. Anal Biochem 1, 344-352.

17. Nabuurs MJA, Hoogendoorn A, van der Molen EJ \& van Osta ALM (1993) Villus height and crypt depth in weaned and unweaned pigs, reared under various circumstances in the Netherlands. Res Vet Sci 55, 78-84.

18. Livak KJ \& Schmittgen TD (2001) Analysis of relative gene expression data using real-time quantitative PCR and $2^{-\triangle \Delta C T}$ method. Methods 25, 402-408.

19. VanderMeer TJ, Wang H \& Fink MP (1995) Endotoxemia causes ileal mucosal acidosis in the absence of mucosal hypoxia in a normodynamic porcine model of septic shock. Crit Care Med 23, 1217-1226.

20. Fink MP, Antonsson JB, Wang HL \& Rothschild HR (1991) Increased intestinal permeability in endotoxic pigs. Mesenteric hypoperfusion as an etiologic factor. Arch Surg 126, 211-218.

21. Verdonk JMAJ, Spreeuwenberg MAM, Bakker GCM \& Verstegen MWA (2001) Nutrient intake level affects histology and permeability of the small intestine in newly weaned piglets. In Digestive Physiology of Pigs, pp. 332-334 [JE Lindberg and B Ogle, editors]. Wallingford, UK: CABI Publishing.

22. Johnson RW (1997) Inhibition of growth by proinflammatory cytokines: an intergrated view. J Anim Sci 75, 1244-1255.

23. Liu YL, Li DF, Gong LM, Yi GF, Gaines AM \& Carroll JA (2003) Effects of fish oil supplementation on the performance and the immunological, adrenal, and somatotropic responses of weaned pigs after an Escherichia coli lipopolysaccharide challenge. J Anim Sci 81, 2758-2765.
24. Kim SW, McPherson RL \& Wu G (2004) Dietary arginine supplementation enhances the growth of milk-fed young pigs. J Nutr 134, 625-630.

25. Takahashi K, Orihashi M \& Yukio A (1999) Dietary L-arginine level alters plasma nitric oxide and apha-1 acid glycoprotein concentrations, and splenocyte proliferation in male broiler chickens following Escherichia coli lipopolysaccharide injection. Comp Biochem Physiol C Toxicol Pharmacol 124, 309-314.

26. Kohli R, Meininger CJ, Haynes TE, Yan W, Self JT \& Wu G (2004) Dietary L-arginine supplementation enhances endothelial nitric oxide synthesis in streptozotocin-induced diabetic rats. J Nutr 134, 600-608.

27. Frank JW, Escobar J, Nguyen HV, Jobgen SC, Jobgen WS, Davis TA \& Wu G (2007) Oral $N$-carbamylglutamate supplementation increases protein synthesis in skeletal muscle of piglets. J Nutr 137, 315-319.

28. Wu G, Meininger CJ, Knabe DA, Bazer FW \& Rhoads JM (2000) Arginine nutrition in development, health and disease. Curr Opin Clin Nutr Metab Care 3, 59-66.

29. Sukumar P, Loo A, Magur E, Nandi J, Oler A \& Levine RA (1997) Dietary supplementation of nucleotides and arginine promotes healing of small bowel ulcers in experimental ulcerative ileitis. Dig Dis Sci 42, 1530-1536.

30. Baker DH (1982) Importance of amino acid balance in swine rations. Feedstuffs 54, 40.

31. Anderson LC, Lewis AJ, Peo ER Jr \& Crenshaw JD (1984) Effects of excess arginine with and without supplemental lysine on performance, plasma amino acid concentrations and nitrogen balance of young swine. J Anim Sci 58, 369-377.

32. Rhoads JM, Chen W, Gookin J, et al. (2004) Arginine stimulates intestinal cell migration through a focal adhesion kinase dependent mechanism. Gut 53, 514-522.

33. Rhoads JM, Niu X, Odle J \& Graves LM (2006) Role of mTOR signaling in intestinal cell migration. Am J Physiol Gastrointest Liver Physiol 291, G510-G517.

34. Oswald IP, Dozois CM, Barlagne R, Fournout S, Johansen MV \& Bogh HO (2001) Cytokine mRNA expression in pigs infected with Schistosoma japonicum. Parasitology 122, 299-307.

35. Marion R, Coëffier M, Lemoulan S, Gargala G, Ducrotté P \& Déchelotte P (2005) L-Arginine modulates CXC chemokines in the human intestinal epithelial cell line HCT- 8 by the NO pathway. Biochimie 87, 1048-1055.

36. Cui XL, Iwasa M, Iwasa Y \& Ogoshi S (2000) Argininesupplemented diet decreases expression of inflammatory cytokines and improves survival in burned rats. JPEN $J$ Parenter Enteral Nutr 24, 89-96.

37. Yeh CL, Yeh SL, Lin MT \& Chen WJ (2002) Effects of arginine-enriched total parenteral nutrition on inflammatoryrelated mediator and T-cell population in septic rats. Nutrition 18, 631-635.

38. Nakajima A, Wada K, Miki H, et al. (2001) Endogenous PPAR gamma mediates anti-inflammatory activity in murine ischemia-reperfusion injury. Gastroenterology 120, 460-469.

39. Cuzzocrea S, Pisano B, Dugo L, et al. (2003) Rosiglitazone and 5-deoxy-delta 12,14-prostaglandin J2, ligand of the peroxisome proliferator-activated receptor-gamma (PPAR-gamma), reduce ischaemia/reperfusion injury of the gut. $\mathrm{Br} J$ Pharmacol 140, 366-376.

40. Katayama K, Wada K, Nakajima A, et al. (2003) A novel PPAR gamma gene therapy to control inflammation associated with inflammatory bowel disease in a murine model. Gastroenterology 124, 1315-1324.

41. Sato N, Kozar RA, Zou L, Weatherall JM, Attuwaybi B, MooreOlufemi SD, Weisbrodt NW \& Moore FA (2005) Peroxisome proliferator-activated receptor gamma mediates protection 
against cyclooxygenase-2-induced gut dysfunction in a rodent model of mesenteric ischemia/reperfusion. Shock 24, 462-469.

42. Moraes LA, Piqueras L \& Bishop-Bailey D (2006) Peroxisome proliferator-activated receptors and inflammation. Pharmacol Ther 110, 371-385.

43. Calkins CM, Bensard DD, Heimbach JK, Meng X, Shames BD, Pulido EJ \& McIntyre RC Jr (2001) L-Arginine attenuates lipopolysaccharide-induced lung chemokine production. Am $J$ Physiol Lung Cell Mol Physiol 280, L400-L408.

44. Desreumaux P, Dubuquoy L, Nutten S, et al. (2001) Attenuation of colon inflammation through activators of the retinoid $\mathrm{X}$ receptor (RXR)/peroxisome proliferator-activated receptor gamma (PPARgamma) heterodimer. A basis for new therapeutic strategies. J Exp Med 193, 827-838. 